\title{
Etude du comportement de neuf cultivars de tomates (Solanum Lycopersicum L.) dans différentes zones agro-écologiques du Burkina Faso pendant l'hivernage.
}

\author{
Ali GARANE ${ }^{1 *}$, Koussao SOME ${ }^{1}$, Jeanne NiKIEMA ${ }^{1}$, Mamoudou TRAORE ${ }^{2}$ et Mahamadou \\ SAWADOGO ${ }^{3}$ \\ ${ }^{1 *}$ Institut de l'Environnement et de Recherches Agricoles (INERA/CREAF-Kamboinse), Département Production \\ Végétale/Programme Cultures Maraîchères, Fruitières, Plantes à Tubercules, 01 BP 470 Onagadongou 01, Burkina Faso. \\ 2Institut de l'Environnement et de Recherches Agricoles (INERA/CREAF-Kamboinsè), Département Gestion des Ressources \\ Naturelles/Système de Production, 03 BP 470 Onagadougou 03, Burkina Faso. \\ ${ }^{3}$ Université Onaga I Pr Joseph KI-ZERBO/Unité de Formation et de Recherche en Science de la Vie et de la Terre \\ (UO/UFR-SVT), Laboratoire de Génétique et Biotechnologie Végétale, 03 BP 7021 Onagadongon 03, Burkina Faso. \\ *Correspondance, courriel:ali_garane@yahoo.fr
}

Mots clés: Tomate, performance, hivernage, maladies, Burkina Faso.

Key words: Tomato, wintering, performance, diseases, Burkina Faso.

Publication date 30/06/2019 http://www.m.elewa.org/JAPS

\section{RESUME}

Objectif: Au cours de la saison hivernale 2014-2015, une étude portant sur neuf cultivars améliorés de tomate a été réalisée dans 5 zones agro-écologiques (Kamboinsè, Loumbila, Komgoussi, Yako et Salgo) du Burkina Faso. Les observations et mesures ont porté sur la sensibilité au flétrissement bactérien, le rendement et ces composants essentiels afin de déterminer les cultivars les mieux adaptés aux conditions de culture d'hivernage dans les zones de l'étude.

Méthodologie et résultats: Le dispositif expérimental est un bloc complet de Fisher randomisé de 4 répétitions avec des traitements constitués des variétés V1, V2, V3, V4, V5, V6, V7, V8 et V9. Les plants ont été repiqués en ligne simple en parcelles élémentaires de $37,5 \mathrm{~m}^{2}$. Les écartements sont de $0,75 \mathrm{~m}$ sur $0,40 \mathrm{~m}$, soit une densité de 33333 pieds/ha. Les variables suivantes de productivité ont été supérieures à Yako pour la densité chez les cultivars Thorgal, Gempride, Jaguard, Mongal, Nadira respectives de 67,75; 71,75; 80,12; 99,5 et 108,75 plants $/ 37,5 \mathrm{~m}^{2}$. A Salgo pour le poids moyen du fruit chez Jaguard (56,06 $\mathrm{g}$ ) Mongal (55,63g), FBT5 (51,1 g) et Thorgal (48,8 g) et à Kongoussi pour Gempride (55,63 g). Les cultivars Rs et Nadira ont observé des rendements meilleurs à Yako respectifs de 28,72 et 28,73 t/ha. A Salgo, les hybrides Gempride, Mongal, FBT5, Jaguard et Thorgal ont été plus performant avec respectivement 21,$65 ; 20,3 ; 20,0 ; 17,46$ et 15,14 t/ha.

Conclusion et application des résultats: Selon la moyenne des rendements, les meilleurs sites ont été par ordres décroissant Yako $(19,044$ t/ha), Salgo $(17,44)$, Kongoussi $(7,06$ t/ha), Loumbila (6,87 t/ha) et Kamboinsè (2,97 t/ha). Dans le même ordre, les meilleures variétés ont été Nadira, Rs, Gempride, Jaguar, Thorgal, Mongal, FBT5 avec respectivement 13,87, 10,$79 ; 10,23 ; 9,66 ; 8,23$ et $7,08 \mathrm{t} / \mathrm{ha}$. Si nous couplons à cela la tolérance aux flétrissements, Jaguar, Nadira et Gempride demeurent les meilleures variétés suivies de Mongal et FBT5. Les résultats obtenus sur les 5 sites ont montré une variabilité importante. Ce qui est peut- 
être du à la maitrise des techniques de production qui n'ont pas été homogènes d'un site à un autre et à la particularité de chaque variété. Pour améliorer la performance de ces variétés, il paraît indiqué de poursuivre les recherches dans une approche agronomique visant la maîtrise de l'eau d'irrigation, une gestion intégrée des ravageurs et maladies pendant le cycle cultural.

\section{ABSTRACT}

Objective: During the winter season 2014-2015, a study of nine improved tomato cultivars was conducted in 5 agro-ecological zones (Kamboinsè, Loumbila, Komgoussi, Yako and Salgo) of Burkina Faso. Observations and measurements focused on susceptibility to bacterial wilt, yield and his essential components to determine the most suitable cultivars for overwintering conditions in the study areas.

Methodology and results: The experimental field is a completely randomising block of 4 repetitions and nine treatments consisting of varieties V1, V2, V3, V4, V5, V6, V7, V8 and V9. The seedlings were transplanted in single rows into $37.5 \mathrm{~m}^{2}$ elementary plots. The spacing was $0.75 \mathrm{~m} \times 0.40 \mathrm{~m}$ with a density of 33333 plants/ha. The following productivity variables were greater than Yako for density respectively for Thorgal, Gempride, Jaguard, Mongal and Nadira cultivars of $67.75 ; 71.75 ; 80.12 ; 99.5$ and 108.75 plants/37.5 $\mathrm{m}^{2}$. In Salgo for the average fruit weight in Jaguard (56.06 g) Mongal (55.63g), FBT5 (51.1 g) and Thorgal (48.8 g) and Kongoussi for Gempride (55.63 g).The Rs and Nadira cultivars in Yako showed higher yields of 28.72 and 28.73 t/ha, respectively. In Salgo, Gempride, Mongal, FBT5, Jaguard and Thorgal hybrids were better at $21.65 ; 20.3 ; 20.0 ; 17.46$ and $15.14 \mathrm{t} / \mathrm{ha}$.

Conclusion and application of results: According to the average yields, the best sites were in descending order Yako (19.04 t/ha), Salgo (17.44 t/ha), Kongoussi (7.06 t/ha), Loumbila $(6.87 \mathrm{t} / \mathrm{ha})$ and Kamboinse $(2.97 \mathrm{t} / \mathrm{ha})$. In the same order, the best varieties were Nadira, Rs, Gempride, Jaguar, Thorgal, Mongal, FBT5 with respectively 13.87, 10.79; 10.23; 9.66; 8.23 and $7.08 \mathrm{t} / \mathrm{ha}$. If we combine this with tolerance to wilting, Jaguar, Nadira and Gempride remain the best varieties followed by Mongal and FBT5. The results obtained on the 5 sites showed significant variability. This may be due to the mastery of production techniques that have not been homogeneous from one site to another. Varietal peculiarity has also been played an important role. To improve the performance of these varieties, it seems appropriate to continue research in an agronomic approach aimed to control irrigation water, integrated pests management and diseases during the crop cycle.

\section{INTRODUCTION}

Au Burkina Faso, la tomate est la deuxième plus importante culture maraîchère après l'oignon. En effet $21 \%$ de la production maraichère totale au Burkina Faso a été attribué à la tomate à la même période (MASA, 2013). Selon FAOSTAT (2016), sa production est estimée à plus de 10000 tonnes en 2014. Elle demeure l'une des spéculations maraîchères la plus exportée dans les pays comme le Ghana, le Togo, le Benin, la Côte d'ivoire et la Guinée Equatoriale (MAHRH 2011). Les recettes d'exportation de l'oignon ont oscillé entre 150 et 245 millions de F CFA entre 2008 et 2011, celles de la tomate sont passées de 596 millions de F CFA à 795 millions de F CFA dans le même intervalle de temps (MASA, 2013). Les principales zones de production sont Yatenga, Sanmatenga, Gnagna et Oubritenga; ces provinces totalisent plus de $22 \%$ de la production nationale. Le deuxième groupe de province est constitué du Kénédougou, du Passoré, du Koulpelogo, du Boulgou, du Zondoma et du Boulkiemdé. De 2006 à 2011, les superficies emblavées en tomate ont 
augmenté de plus de $80 \%$ passant de 5224 ha à 9529 ha (MASA, 2013). Cependant, depuis des décennies, la culture de la tomate est essentiellement faite en saison sèche en raison de l'absence ou de l'inaccessibilité de variétés adaptées à la saison pluvieuse. Au cours de ces dernières années, la recherche scientifique a travaillé sur l'évaluation de nouvelles variétés de tomate importées à nos conditions agroécologiques de saison pluvieuse et à la création de nouvelles variétés Farako-Bâ Tomate (FBT1,

\section{MATERIEL ET METHODES}

3.1 Choix des Sites d'étude: Par souci de comparaison, au cours des saisons maraîchères 2014-2015, les études réalisées concernent quatre sites maraîchers du Burkina Faso appartenant à trois région territoriales dont le plateau central (Loumbila, Salogo), centre-nord (Kongoussi) et le nord (Yako) qui concentrent jusqu'a 31,4\% (51891 ha) des effectifs maraichers national, environ $32 \%$ des superficies saisonnières ( 8973 ha) et $28 \%$ de la production maraîchère nationale soit environ 220825 tonnes (MASA, 2013).

3.1.1 Le site de Loumbila (région du Centre): Le climat est de type soudanien avec une pluviométrie moyenne annuelle variant entre 700 et $800 \mathrm{~mm}$, Les températures sont assez élevées et varient de $16^{\circ} \mathrm{C}$ en décembre (minimum journalier) à un maximum de $40^{\circ} \mathrm{C}$ mars et avril. La production maraîchère de 33523 t (44572 t pour la région) est dominée par l'oignon à bulbes (17232 tonnes) et la tomate 7887 tonnes (MASA, 2013).

3.1.2 Le site de Salgo (Plateau Central): Le climat est de type nord-soudanien, la saison pluvieuse dure de mai-juin à septembre-octobre soit une durée moyenne de 4 mois, la pluviosité annuelle de $500-800 \mathrm{~mm}$ est très irrégulière avec une mauvaise répartition. Les températures les plus élevées oscillent entre 39 et $45^{\circ} \mathrm{C}$ situées entre les mois de mars et mai tandis que les plus basses $\left(16\right.$ à $\left.19^{\circ} \mathrm{C}\right)$ sont atteintes aux mois de novembre et février, Juillet et août sont généralement les plus pluvieux la région pour une production maraîchère de 4827 tonnes et l'oignon à bulbes
FBT2 et FBT3, FBT3 FBT5) créées par Institut de l'Environnement et de Recherches Agricoles (INERA) afin d'augmenter la disponibilité de ce légume en période d'hivernage. Le présent travail cherche à testé et a évaluer les performances des cultivars de tomate pour leur tolérance au flétrissement bactérien et leur rendement dans différentes conditions agroécologiques de saison pluvieuse de Burkina Faso.

(4107 tonnes), la tomate (118 tonnes) et le chou (498 tonnes) sont les productions majeures (MASA, 2013).

3.1.3 Le site de Kongoussi (région du Centre Nord): Il appartient au climat de transition sahélo-soudanien avec une pluviosité annuelle de 600-700 $\mathrm{mm}$. La saison sèche est de 7- 8 mois, les températures maximales s'observent entre mars et avril avec des moyennes de $41^{\circ} \mathrm{C}$ et les températures minimales en janvier avec des moyennes qui varient de 14 à $17^{\circ} \mathrm{C}$. Les superficies maraîchères représentent 826 ha sur les 2249,26 ha dont dispose la région. La production maraîchère dans la province de 13849 tonnes se compose en grande partie de l'oignon à bulbes (8794 tonnes), et de la tomate 2603 tonnes (MASA, 2013).

3.1.4 Le site de Yako (région du Nord): Le climat de type tropicale sec se caractérise par une saison de pluie de juin à octobre avec des précipitations d'environ $650 \mathrm{~mm} / \mathrm{an}$ et un saison sèche de novembre a juin d'une durée 7 mois. Les superficies maraîchères d'environ 714 ha enregistrent une production maraîchère de 17347 tonnes composée en majorité de l'oignon à bulbes (9385 tonnes), et de la tomate pour 6868 tonnes (MASA, 2013).

3.2 Matériel végétal: Le matériel végétal est constitué de neuf (9) cultivars de la tomate (Solanum Lycopersicum L.) dont huit (8) variétés hybrides F1 Gempride, Jaguar, Lindo, Nadira, Mongal, Progress, Thorgal, RS 01658654. La variété locale FBT5 constitue le 
témoin. Les caractéristiques essentielles des variétés sont présentées dans le Tableau 1.

Tableau 1: Description du Matériel végétal utilisé

\begin{tabular}{|c|c|c|c|c|}
\hline Variété & Origine & $\begin{array}{l}\text { Préciosié } \\
\text { (1ièrerécolte) }\end{array}$ & $\begin{array}{l}\text { Poids moyen } \\
\text { fruit }\end{array}$ & Caractéristiques essentielles \\
\hline $\begin{array}{l}\text { Gempride } \\
\text { F1 }\end{array}$ & $\begin{array}{l}\text { Seminis } \\
\text { Thailande }\end{array}$ & moyenne & 80 à $100 \mathrm{~g}$ & $\begin{array}{l}\text { Très vigoureuse, Fruit : rond, très ferme; } \\
\text { résistance au TYLCV, au virus de la } \\
\text { mosaïque de la tomate, à la fusariose; } \\
\text { adaptée à la saison fraîche. }\end{array}$ \\
\hline Jaguar F1 & \multirow{5}{*}{$\begin{array}{l}\text { Tropicasen/ } \\
\text { Technisem } \\
\text { Sénégal }\end{array}$} & $65 \mathrm{JAR}$ & 100 à $110 \mathrm{~g}$ & $\begin{array}{l}\text { Productivité élevée; Fruit : Forme ovale, } \\
\text { bonne fermeté; Bonne tolérance au } \\
\text { TYLCV et au Fusarium oxysporum }(0 \text { et } 1) \text {; } \\
\text { adaptée aux cultures en saison sèche fraiche } \\
\text { et chaude. }\end{array}$ \\
\hline Nadira F1 & & 65 à $70 \mathrm{JAR}$ & 85 à $90 \mathrm{~g}$ & $\begin{array}{l}\text { Fruit: ovale, bonne fermeté ; Haute } \\
\text { tolérance au TYLCV, Fusarium oxysporum (0 } \\
\text { et 1); adaptée à la saison fraiche et chaude, } \\
\text { et hivernage. }\end{array}$ \\
\hline Mongal F1 & & $65 \mathrm{JAR}$ & 100 à $120 \mathrm{~g}$ & $\begin{array}{l}\text { Fruit : aplati et légèrement côtelé, } \\
\text { excellente tolérance au flétrissement } \\
\text { bactérien; résistance au TMV (0), au } \\
\text { Fusarium FOL ( } 0 \text { et } 1) \text {, FORL; adaptée à la } \\
\text { saison très chaude et à l'hivernage. }\end{array}$ \\
\hline Lindo F1 & & $65 \mathrm{JAR}$ & $90 \mathrm{~g}$ & $\begin{array}{l}\text { Fruit: Forme carrée longue, bonne fermeté; } \\
\text { très bonne résistance au flétrissement } \\
\text { bactérien, au TMV) et au Fusarium (fol, 0); } \\
\text { adaptée aux cultures en hivernage, }\end{array}$ \\
\hline Thorgal F1 & & $65 \mathrm{JAR}$ & 120 à $130 \mathrm{~g}$ & $\begin{array}{l}\text { Fruit: ronde, bonne fermeté; très bonne } \\
\text { tolérance au flétrissement bactérien, au } \\
\text { TMV (0), au Fusarium oxysporum f, sp, } \\
\text { lycopersicum (fol, 0); adaptée à la saison } \\
\text { chaude et à l'hivernage. }\end{array}$ \\
\hline $\begin{array}{l}\text { Progress } \\
\text { F1 }\end{array}$ & \multirow{2}{*}{$\begin{array}{l}\text { Monsanto } \\
\text { Bayer }\end{array}$} & Précoce & $70 \mathrm{~g}$ & $\begin{array}{l}\text { Très vigoureuse } ; \text { Resistante au ASC } \\
\text { (Alternaria alternata f. sp. Lycopersici) } \\
\text { Fusarium oxysporum }(0 \text { et } 1) .\end{array}$ \\
\hline $\begin{array}{l}\text { RS } \\
01658654 \\
\text { F1 }\end{array}$ & & Moyenne & $65 \mathrm{~g}$ & $\begin{array}{l}\text { Très vigoureuse ; fruit de Forme ronde, } \\
\text { bonne fermeté; résistance à la verticilliose }\end{array}$ \\
\hline $\begin{array}{l}\text { Farako-Ba } \\
\text { Tomate } \\
\text { (FBT5) }\end{array}$ & INERA & $80 \mathrm{JAR}$ & $90-95 \mathrm{~g}$ & $\begin{array}{l}\text { Fruit de couleur rouge; rendement } \\
\text { potentiel } 40-45 \mathrm{t} / \text { ha ; bonne résistance aux } \\
\text { coups de soleil et aux éclatements de fruits } \\
\text { adaptée aux cultures d'hivernage. }\end{array}$ \\
\hline
\end{tabular}

3.3 Le dispositif expérimental: Deux types de dispositifs ont été utilisés pour ces tests.

3.3.1 En station (site de Kamboinsè) à Ouagadougou: Le dispositif expérimental (Figure 1) est constitué par un bloc complet de Fisher randomisées avec 4 répétitions. Ce dispositif comprend 36 répétitions composées de 9 sous blocs répétés 4 fois chacun et comportant chacun les 9 traitements (variétés) en parcelles élémentaires de $12 \mathrm{~m}^{2}$ (4 billons x 4 $\mathrm{m} \times 0,75 \mathrm{~m})$ à raison de $0,4 \mathrm{~m}$ entre pied sur la ligne et $0,75 \mathrm{~m}$ entre les lignes. Pour chaque traitement, $48 \mathrm{~m}^{2}\left(12 \mathrm{~m}^{2} \times 4\right)$ seront utilisés. 
L'écartement entre bloc et entre les sous bloc est de $1 \mathrm{~m}$. La longueur de la parcelle est de 35 $\mathrm{m}$ pour $19 \mathrm{~m}$ de largeur, soit une surface totale de $665 \mathrm{~m}^{2}$ sans les bordures pour une superficie utile de $432 \mathrm{~m}^{2}\left(48 \mathrm{~m}^{2}\right.$ x 9 traitements) pour l'essai. Le nombre de plants par ligne de $4 \mathrm{~m}$ de long est de 10 (laisser $10 \mathrm{~cm}$ de part et d'autre de la ligne), soit 40 plants/parcelle élémentaire, 160 plants /traitement et 1440 plants pour le test, soit une densité de 33333 plants/ha.
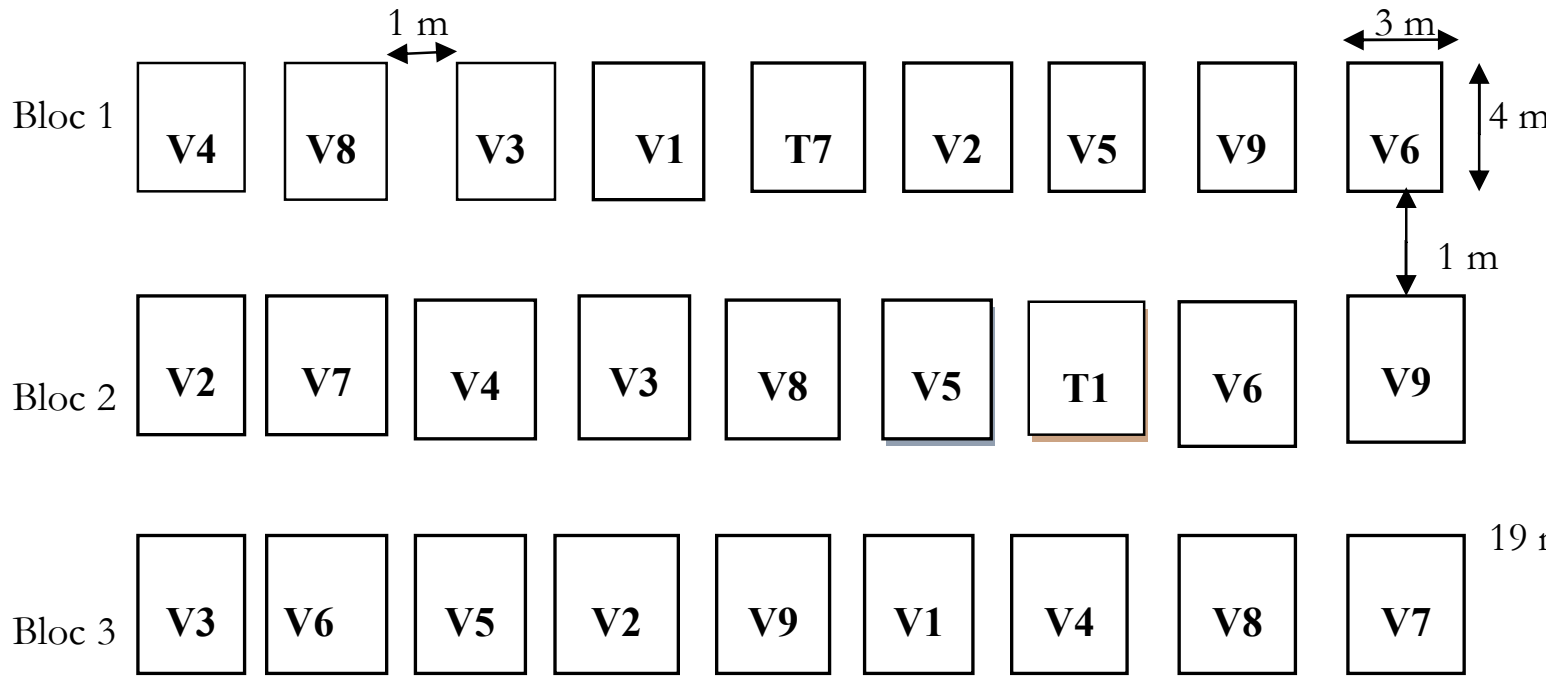

$19 \mathrm{~m}$

Bloc 4
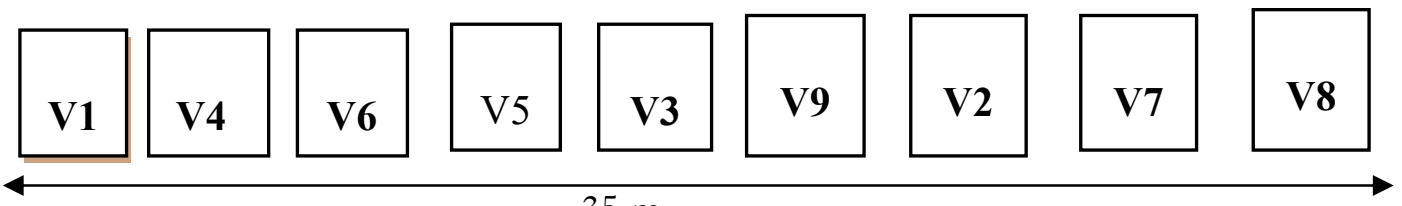

$35 \mathrm{~m}$

Figure 1: Dispositif expérimental utilisé

V1= Gempride; V2 = Jaguard; V3 = Nadira; V4 = Mongal; V5 = Progess; V6 = Thorgal; V7 = RS V8 = Lindo; V9 = FBT5

3.3.2 En milieu paysan: Dans chaque site de production (Salgo, Yako, Komgoussi et Loumbila) situées dans un rayon de $150 \mathrm{~km}$ de Ouagadougou), quatre (4) producteurs étaient installés sur le même site. Chacun exploitant les neufs (9) variétés de tomate. Chaque parcelle cultivée était prise comme un traitement. Ainsi, les 4 répétitions étaient constituées par les 4 producteurs. Chaque répétition ou parcelle de mesure couvrait une superficie de $108 \mathrm{~m}^{2}$ [(4 billons de $4 \mathrm{~m} \times 0,75 \mathrm{~m}) \times$ 9]. Les parcelles élémentaires étaient distantes de $1 \mathrm{~m}$. Les écartements entre les plants étaient de $0,75 \mathrm{~m}$ entre les lignes et de $0,4 \mathrm{~m}$ sur la ligne.

\subsection{Conduite de l'essai :}

3.4.1 Préparation du sol: Le labour a été effectué à l'aide d'une charrue à kamboinsè (Ouagadougou) et dans quatre zones de production de la tomate (Salgo, Yako Komgoussi et Loumbila) avec une charrue bovine. Une fumure de fond constituée de 20 t/ha pour le fumier et $450 \mathrm{~kg} / \mathrm{ha}$ d'engrais minéral (NPK, 14-23-14) a été incorporée au sol à l'aide d'une houe et d'un râteau. En deux épandages, $200 \mathrm{~kg} / \mathrm{ha}$ d'urée ont été appliqués par parcelle élémentaire comme fumure d'entretien, soit la moitié à la reprise des plants (21 jours après repiquage) et l'autre moitié à l'apparition des premiers fruits (45 jours après repiquage). 
3.4.2 Semis en pépinière: Pour la mise en place du test $110 \mathrm{~g}$ de semence ont été nécessaire, soit environ $22 \mathrm{~g}$ pour chaque site et $3 \mathrm{~g}$ pour chacune des variétés. Les pépinières ont été installées pour l'ensemble des sites dans des bacs métalliques dans la 1ère décade de juin 2014 en terre désinfectée au préalable à la chaleur. Pour permettre une bonne aération des plants et leur meilleur développement, les graines de tomate ont été semées dans des sillons ouverts à l'aide d'un morceau de bois et espacés de $15 \mathrm{~cm}$ avec $5 \mathrm{~cm}$ entre les poquets dans le sillon. Après le semis, pour éviter les actions directes des eaux de pluie sur les jeunes pousses, un toit recouvert de film plastique a été dressé des bacs.

3.4.3 Repiquage: Les plantules de tomates ont été repiquées sur des billons en fin de la 3è décade de juin à la $1^{\text {ère }}$ décade de juillet 2014, soit environ 25-30 jours après le semis en fonction des sites. Chaque variété a été repiquée sur 4 billons de $4 \mathrm{~m}$ chacun dans un dispositif complet randomisé avec quatre répétitions. Le traitement phytosanitaire appliqué sur les parcelles était identique sur l'ensemble des sites de production. Tous les 15 jours, la Deltaméthrine a été utilisé comme insecticide (1 $1 /$ ha) et le manèbe comme fongicide (3,5 $\mathrm{kg} / \mathrm{ha})$. En fonction du site et du degré d'enherbement des parcelles, 4 à 6 sarclages manuels ont été réalisés pour éliminer les mauvaises herbes pendant la culture.

3.4.4 Récoltes: En fonction des sites, les récoltes ont eu lieu de la 3è décade du mois

\section{RESULTATS}

4. 1 Effet du site et de la variété sur le nombre de plants récoltés: La Figure 2 présente l'évolution du nombre de plants de tomate récoltés par traitement en fonction du site et de la variété. Les plants issus de toutes les variétés ont été sensibles aux variations du site de culture, aussi, des différences très significatives $(\mathrm{P}<0,0001)$ ont été observées entre les différents sites de production. Indépendamment du cultivar, la densité moyenne de 81,9 plants par traitement a été plus importante à Yako et faible à Salgo (37,2 d'aout à la 3è décade d'octobre 2014 Les tomates ont été récoltées à raison de deux récoltes par semaine (stade fruits tournants).

3.5 Paramètres mesurés: La prévalence de la maladie a été évaluée à partir de la troisième semaine après transplantation. Les plants flétris très jeunes ou avant la floraison ont été marqués par des étiquettes. Les fragments de plants ont été incubés sur du papier buvard humidifié, puis, les champignons qui s'y sont développés ont été identifiés au laboratoire. $\mathrm{La}$ détection de bactéries notamment l'infection par Ralstonia solanacearum s'est faite également en plaçant la section transversale d'une tige malade dans un verre d'eau. L'excrétion des bactéries $\mathrm{du}$ tissu malade se traduit par décoloration blanche progressive du liquide. Au niveau des variables de productivité, il a été question dans chaque traitement de compter le nombre de plants récoltés (Nbptrec); le nombre moyen de fruits par plant (Nbfrtpt): nous avons procédé au comptage des fruits de chaque cueillette et pour chaque plant; le poids moyen du fruit (PdMfrt): il a été calculé à partir de la production par plant/nombre de fruits du même plant. La mesure est donnée en gramme (g) et enfin le rendement réel fruit ( $\mathrm{RdtFr})$ ou rendement total par parcelle a été estimé par récolte et pesée échelonnée de tous les fruits mûrs de tomates exprimé en kilogramme $(\mathrm{kg})$. Les mesures de poids ont été faites à l'aide d'une balance électronique.

plants). Les sites de Komgoussi, Loumbila et Kamboinsè ont observé des moyennes très faibles pour ce paramètre respectives de 19,9; 19,6 et 9,25 plants/traitement. Par contre, l'évolution de cette variable a montrée des différences très significatives $(p=0,006)$ entre les variétés. Par ordre croissant, les cultivars Thorgal (67,75 plants), Gempride (71,75 plants), Jaguard (80,12 plants), Mongal (99,5 plants) et Nadira (108,75 plants) ont observé leur plus forte densité moyenne à Yako. A Salgo, les variétés FBT5, Lindo et Rs01658654 
ont observé leurs meilleures performances respectives de 30,37; 33,62 et 45 plants/traitement. En outre, contrairement aux sites de Kamboinsè, Kongoussi et Loumbila, les cultivars Mongal (42,62 plants), Jaguard (46 plants), Nadira (46,12 plants) et Gempride (50,87 plants) ont conservé des densités moyennes relativement plus importantes. Globalement, les tomates Nadira, Jaguard et Mongal ont observé leurs plus faibles densités à
Kamboinsè respectives de 10,$75 ; 10$; et 6,75 plant/traitement. Par rapport a ce site, Loumbila pour cette variable a été légèrement meilleure pour les tomates Nadira (24,2 plants), Jaguard (23,2 plants), Gempride (20 plants), Rs01658654 (18,6 plants) et Mongal (17,9 plants). L'interaction site et variétés a été non significative sur le nombre total de plants récoltés $(\mathrm{P}=0,1639)$

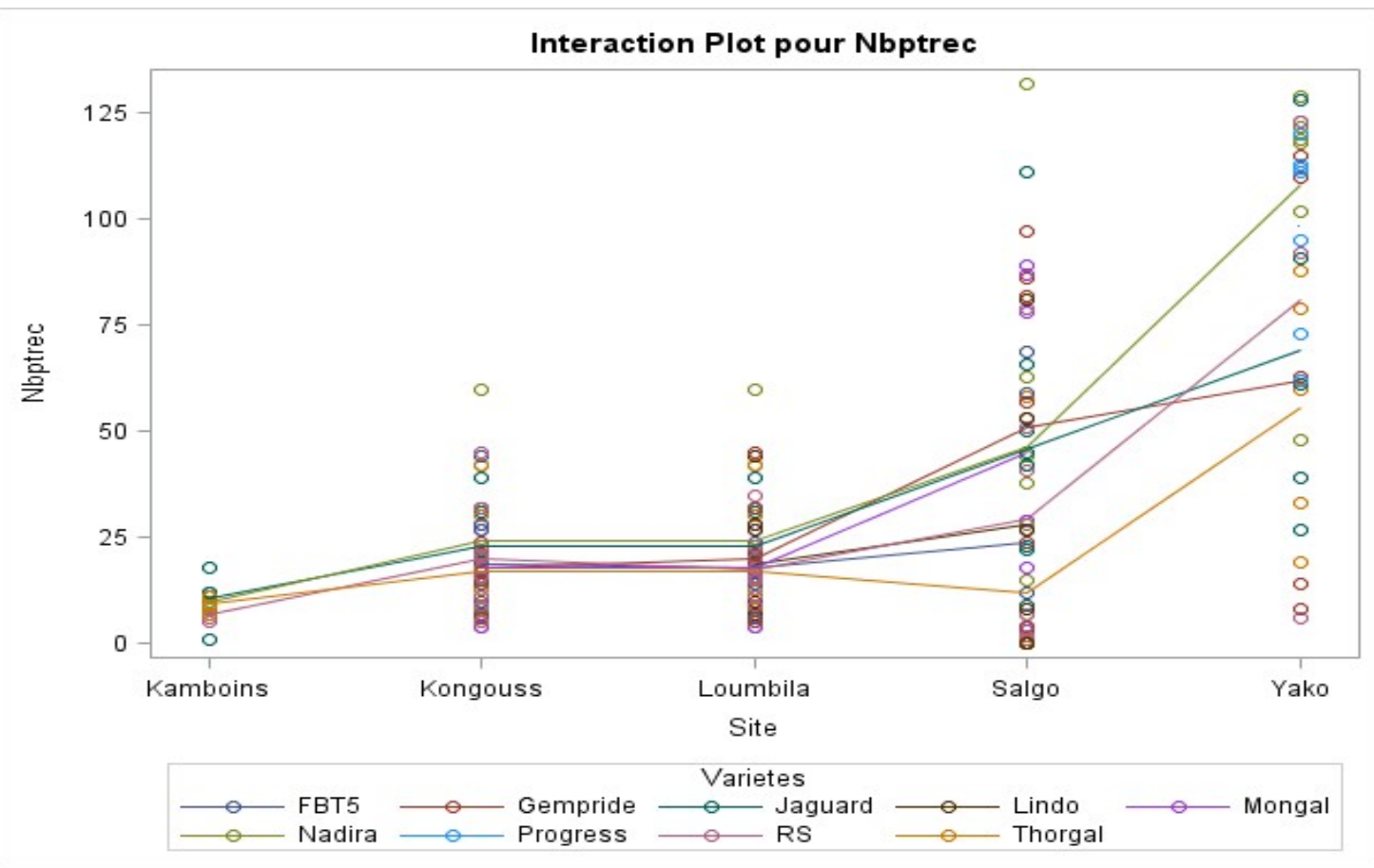

Figure 2 : Effet du site et de la variété sur la densité de plantes récoltée par variété

$\begin{array}{llllll}\text { Source } & \text { DDL } & \text { Type III SS } & \text { Moyenne quadratique } & \text { Valeur F } & \operatorname{Pr}>\text { F } \\ \text { Site } & 4 & 74729,98353 & 18682,49588 & 39,04 & <, 0001 \\ \text { Variétés } & 8 & 10645,74230 & 1330,71779 & 2,78 & 0,0060 \\ \text { Site*Variétés } & 20 & 12693,58097 & 634,67905 & 1,33 & 0,1639\end{array}$

4.2 Effet du site et de la variété sur le nombre moyen de fruits par plant (Nbfrtpt): Le comptage du nombre de fruits par plant a été effectué à chaque récolte. Les résultats obtenus sont représentés par la Figure 3. Aucune différence significative $(p=0,4741)$ n'a été enregistrée entre les sites de production pour cette variable. Le nombre moyen de fruits par plant par site a été de 7,4 à Kongoussi, 7,16 à Lounbila et de 5,35 à Kamboinsé. Les sites de Yako et Salogo ont enregistré en moyenne 6,23 et 6,51 fruits/plant respectivement. Par cultivar de tomate, le nombre moyen de fruit par plant a très peu varié et aucune différence significative $(\mathrm{p}=0,1394)$ n'a été enregistrée. Ainsi, à Kamboinse ce paramètre a évolué de 3,12 fruits (Mongal) à 7,3 fruits (Nadira). Les tomates Jaguard et Thorgal ont enregistré 6,2 et 4,8 
fruits respectivement. A Yako, il a varié de 6,35 fruits (Thorgal) à 5,1 (Mongal). Les cultivars Nadira, Jaguard, Gempride, ont observé 6,3; 5,94 et 5,6 fruits/plant respectivement. Le site de Loumbilaa observé une légère amélioration pour ce paramètre qui a évolué de 4,42 fruits (Thorgal) à 12,9 fruits/plant (Gempride). Les cultivars Nadira $(7,92)$ et Lindo (7,87 fruits) ont observé des valeurs sensiblement égales; tandis que FBT, Mongal et Jaguar avaient des valeurs presque identiques respectives de 5,8 fruits,
5,49 fruits et 5,36 fruits/plants. A Salgo, la variété Gempride (10,48 fruits/plant) a été plus performante. Les cultivars Nadira (7,95 fruits/plant) et Jaguard (7,85 fruits/plant) ont observé une légère amélioration de leur valeur. Les variétés restantes (Mongal, Thorgal Lindo et Progress) ont enregistré 6,63; 6,11; 5,36; 4,83 et de 2,5 fruits/plant respectivement. L'interaction site et variétés a été non significative sur le nombre de fruits récoltés par plant $(\mathrm{P}=0,1100)$.

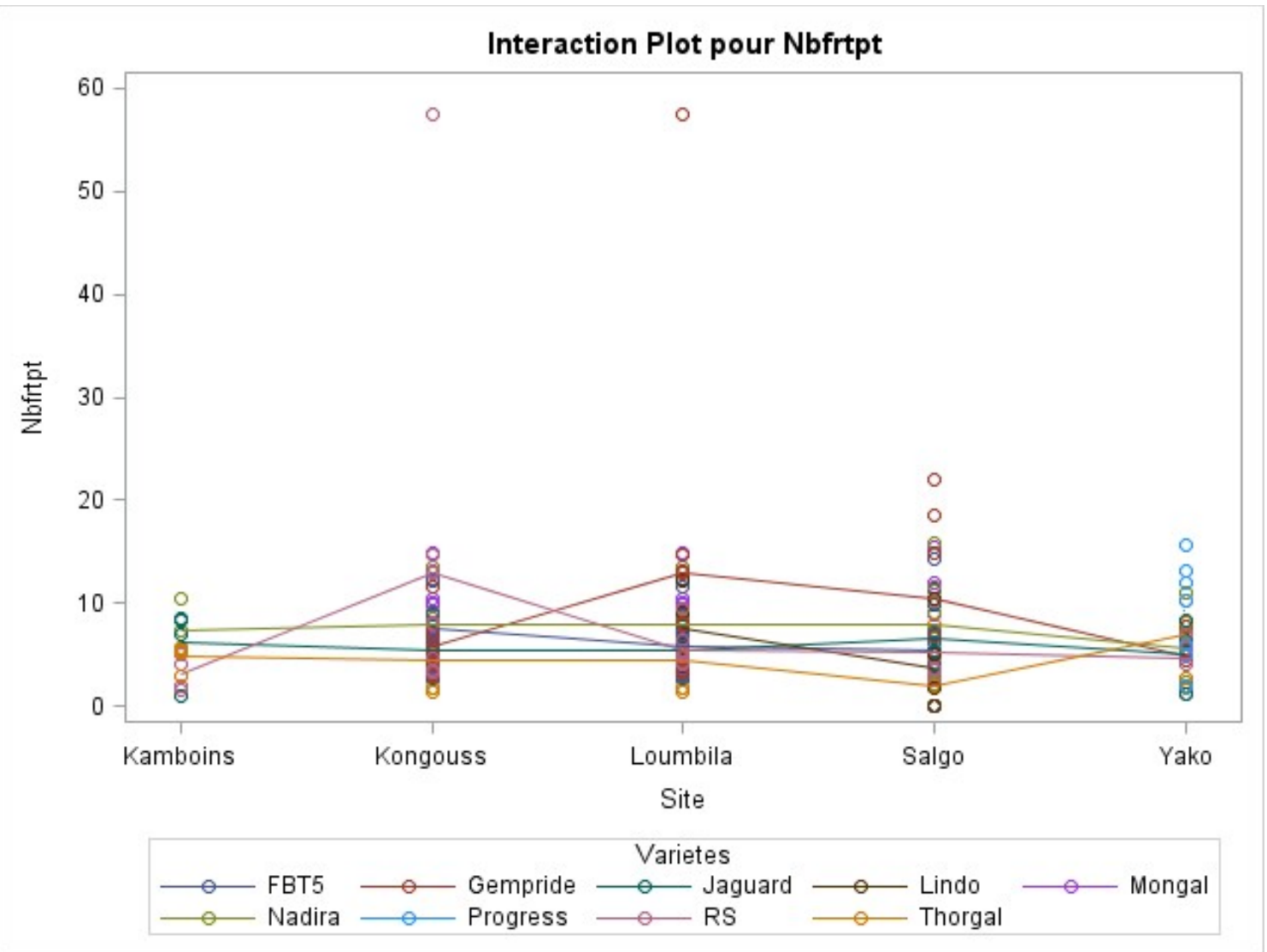

Figure 3 : Effet du site et variété sur le nombre de fruits récoltés par plant (Nbfrtpt)

$\begin{array}{llllll}\text { Source } & \text { DDL } & \text { Type III SS } & \text { Moyenne quadratique } & \text { Valeur F } & \operatorname{Pr}>\text { F } \\ \text { Site } & 4 & 112,0601437 & 28,0150359 & 0,88 & 0,4740 \\ \text { Variétés } & 8 & 394,2133007 & 49,2766626 & 1,56 & 0,1394 \\ \text { Site*Variétés } & 20 & 905,7875005 & 45,2893750 & 1,43 & 0,1100\end{array}$

4.3 Effet du site et de la variété sur le poids moyen du fruit (PdMfrt): Le poids moyen du fruit a été très hétérogène par site de production. L'analyse de la variance de ce paramètre montre une différence très hautement significative $(\mathrm{p}<0001)$ entre les sites de culture (Figure 4). Le poids moyen du fruit a été élevé à Kamboinsè $(60,0 \mathrm{~g})$. Aucune différence majeure de cette variable n'a été observée à Loumbila et Komgoussi avec 49,11 
$\mathrm{g}$ et $48,19 \mathrm{~g}$ respectivement. Les sites de Salgo respectives de 38, 96 et 37, $28 \mathrm{~g}$. et Yako ont enregistré les plus faibles valeurs

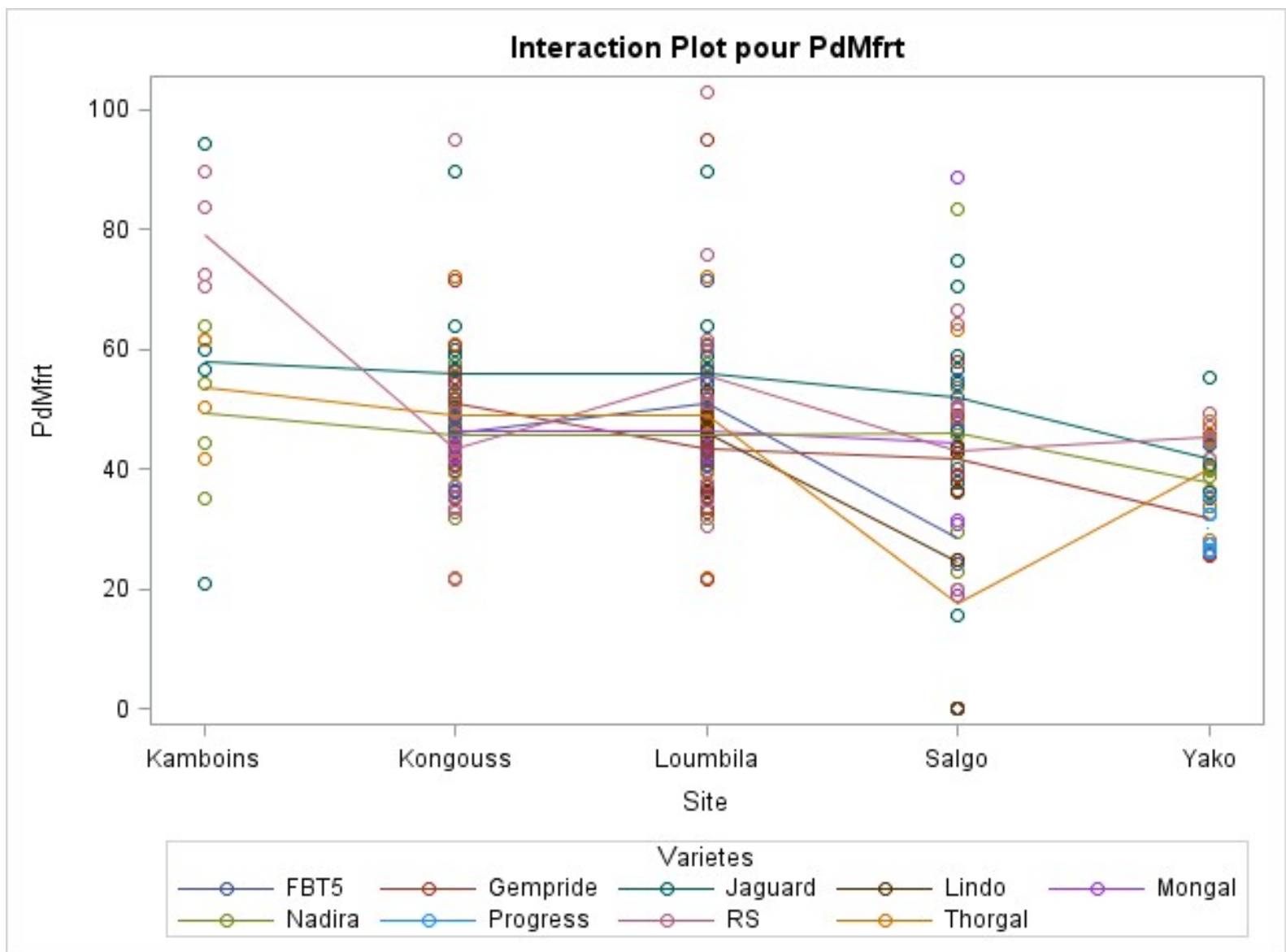

Figure 4 : Effet du site et variété sur le poids moyen du fruit récoltés (PdMfrt)

$\begin{array}{lrrrrr}\text { Source } & \text { DDL } & \text { Type III SS } & \text { Moyenne quadratique } & \text { Valeur F } & \text { Pr }>\text { F } \\ \text { Site } & 4 & 8830,714390 & 2207,678597 & 10,28 & <, 0001 \\ \text { Variétés } & 8 & 5347,552732 & 668,444092 & 3,11 & 0,0024 \\ \text { Site*Variétés } & 20 & 7465,850225 & 373,292511 & 1,74 & 0,0290\end{array}$

L'analyse de la variance sur le poids moyen du fruit révèle une différence hautement significative entre les différents cultivars $(\mathrm{P}=0,0024)$. A Kamboinsè, le poids moyen du fruit variait entre 49,4 g (Nadira) et 78,97 g (Mongal). Les variétés Thorgal et Jaguard avaient 53,72 et 57, $9 \mathrm{~g}$ respectivement. Sur la grande majorité des sites, la tomate Jaguard pour cette variable a observé une valeur stable et en hausse légère d'environ (58 g). Le site de Salgo a observé un poids moyen du fruit sensiblement plus faible pour les cultivars
Thorgal (28,95 g), Lindo (33,10 g) et FBT5 $(38,09 \mathrm{~g})$. Les variétés Gempride $(41,75 \mathrm{~g})$, Mongal (43,46 g), Rs (44,45 g), Nadira (46,06 g) et Jaguard $(51,58 \mathrm{~g})$ pour cette variable ont été légèrement meilleurs. Pour ce paramètre, les valeurs observées par les hybrides Gempride $(29,19$ g), Nadira (31,36 g) et Jaguard (38,39 g) ont été plus faible à Yako. Comparativement à Salgo, cette variable a été meilleure pour Thorgal (40,07 g) et Mongal (45,92 g), tandis que la tomate Jaguard (40,14 g) observait sa plus faible performance sur l'ensemble des sites. 
A Kongoussi, les cultivars Gempride, Jaguard et Thorgal ont observé des poids moyen du fruit importants respectifs de 55,63; 56,06 et 51,1 g. Chez les variétés FBT5, Lindo Nadira et Rs01658654, ces variable respectives de 48,8; 46,28; 46,06 et 45,65 g ont été pratiquement identiques. Par rapport aux autres variétés, les cultivars Jaguard (56,06 g) Mongal (55,63 g), FBT5 (51,1 g) et Thorgal (48,8 g) avaient des fruits de poids moyen nettement supérieurs à Loumbila. De même, les variétés Rs01658654 (46,1 g), Lindo (45,65 g) et Gempride (43,28 g) ont enregistré leur meilleure performance sur ce dernier site. L'interaction site et variétés a été très significative sur le poids moyen des fruits récoltés $(\mathrm{P}=0,0290)$.

4.4 Effet du site et de la variété sur le rendement fruit (RdtFr): La figure 5 présente l'évolution $\mathrm{du}$ rendement moyen fruit en fonction de la variété et du site de production. L'analyse de la variance sur les rendements n'a pas révélée une différence significative $(\mathrm{p}=$ 0,3564) entre les différents variétés de tomates cultivées. Par contre, il est ressorti que les rendements ont varié différemment d'un site de production à un autre. L'influence du site de production sur le rendement des variétés de tomates a été très hautement significative $(\mathrm{P}<$ 0,0001). Le site de Yako a observé le plus fort rendement fruit moyen de 19,04 t/ha. Sur ceux de Salgo, Komgoussi et Lounbila ce sont respectivement 9,44; 7,06 et 6,87 t/ha. Le site de kamboinsè a été le moins performant avec en moyenne de $2,97 \mathrm{t} / \mathrm{ha}$. Les variétés, Gempride (21,65 t/ha), Mongal (20,3 t/ha), FBT5 (20,0 t/ha), Jaguard (17,46 t/ha), Thorgal $(15,14 \mathrm{t} / \mathrm{ha})$ et Lindo $(9,68 \mathrm{t} / \mathrm{ha})$ ont observé à Salgo leur plus forte performance. Bien que les rendements des tomates Rs01658654 et Nadira respectifs de 17,42 et 17,9 t/ ha soient excellents à Salgo, ces dernières ont été plus performantes à Yako avec 28,72 et 28,74 t/ha respectivement. Pour cette variable les tomates Gempride, Jaguard et Thorgal ont enregistré respectivement de $22,00,18,6$ et 14,84 t/ha. A Loumbila, Les différents cultivars ont été peu performants. Les rendements chez Nadira (9,72 t/ha), Mongal (6,77 t/ha) et Thorgal (4,4 t/ha), sont restés identiques à ceux observés à kongoussi, tandis que, les cultivars FBT5 (5,63 t/ha), Jaguard (7,15 t/ha), Gempride (7,5 t/ha) et Rs (7,8 t/ha) ont observé leurs plus faibles valeurs sur l'ensemble des sites. Le site de Kamboinsè avait les plus faibles rendements de l'essai. Les cultivars Jaguard, Nadira, Thorgal et Mongal ont enregistré respectivement 5,13; 3,$33 ; 2,4$ et $1,6 \mathrm{t} / \mathrm{ha}$. L'interaction site et variétés n'a pas été significative sur le rendement fruit récoltés $(p=0,9933)$. 


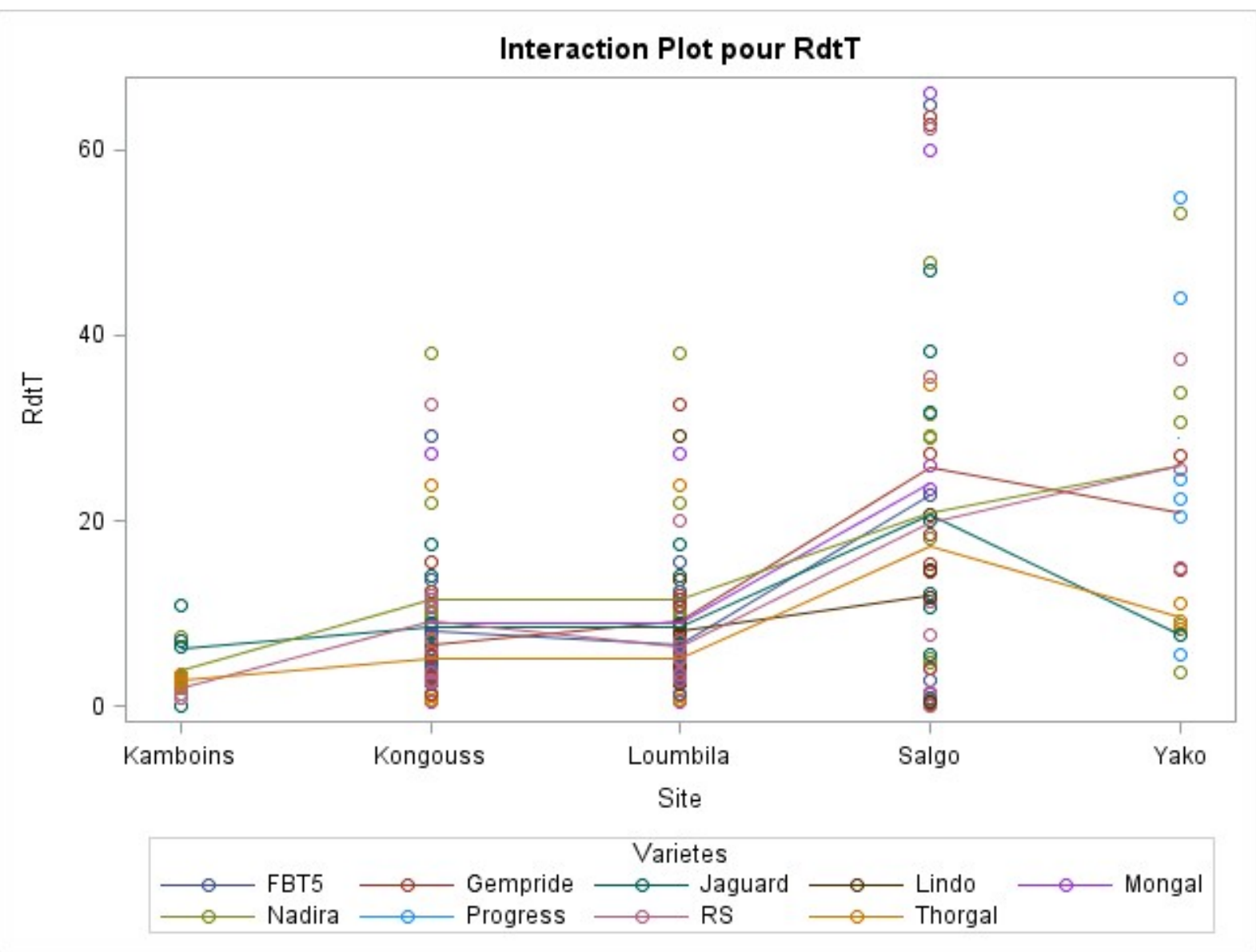

Figure 5 : Effet du site et de la variété sur le rendement fruit récoltés ( $\mathrm{RdtFr}$ )

Source

Site

Variétés

Site*Variétés
DDL

$$
4
$$

8

20

4.5 Effet du site et de la variété sur les taux de maladies foliaires et de mortalité plants: Les taux de maladies foliaires et de mortalité des plants sont représentés dans le Tableau 2. Par site de production, les proportions moyennes de plantes présentant des symptômes foliaires observées trois semaines après le repiquage ont été de $3,47 \%$ à Yako, 7,17\% à Loumbila, 7,19 à Kongoussi, $15,83 \%$ à Kamboinsè et 14,16\% sur le site de Salgo. Par cultivar, Les pourcentages de maladies foliaires observés ont évolué à Kongoussi de 4,82\% (Nadira) - 9,19\% (Rs), à Yako de 2,08\% (Mongal) - 7,29\% (Rs), à
Moyenne quadratique

Valeur F Pr $>$ F

1483,645836
167,848035
57,241748

$9,83<, 0001$

$1,11 \quad 0,3564$

$0,38 \quad 0,9933$
Loumbila de 4,63\% (Rs) - 10,58\% (Mongal), à Kamboinsè de 0,57\% (Thorgal) - 17,54\% (Nadira) et à Salogo de 9,48\% (Rs01658654) $15,15 \%$ (FBT5). Pour les différents cultivars, les pourcentages de perte des plants ont varié de 0 à $7,53 \%$ à Yako, 2,49 à 16,43\% à Kamboinsè, 3,75 à 20,32\% à Kongoussi, 1,4 à 6,8\% à Salgo et de 12,0 à $44,48 \%$ à Loumbila. Les variétés Mongal et Thorgal ont présenté des taux de mortalité élevés à Kongoussi respectifs de 20,32 et $32,12 \%$. A Loumbila, outre Thorgal $(28,9 \%)$, les cultivars Rs01658654 (44,48\%), Lindo $(35,94 \%) \quad$ Gempride $(28,94 \%)$ et FBT5 $(28,87 \%)$ ont également subi des pertes 
importantes de plants, tandis qu'à Kamboinsè, Thorgal, Gempride et Rs ont présenté des taux plus élevés de pertes respectifs de 16,19,16,32 et $16,43 \%$. La comparaison entre les différents sites a révélé que Loumbila $(26,4 \%)$ de taux moyen de mortalité des plantes, est le site le plus affecté par les flétrissements des plants. Les sites de Salgo (14,16\%) et Kongoussi $(11,05 \%)$ occupent la seconde et troisième place respectivement.

Tableau 2: Taux de maladies foliaires et de mortalité des plants

\begin{tabular}{|l|c|c|c|c|c|c|c|c|c|c|}
\hline \multirow{2}{*}{$\begin{array}{l}\text { Variétés } \\
\text { de tomate }\end{array}$} & \multicolumn{2}{|c|}{ Kongoussi } & \multicolumn{2}{|c|}{ Yako } & \multicolumn{2}{|c|}{ Loumbila } & \multicolumn{2}{|c|}{ Kamboinsè } & \multicolumn{2}{c|}{ Salgo } \\
\cline { 2 - 10 } & $\begin{array}{c}\text { MF } \\
\mathbf{( \% )}\end{array}$ & $\begin{array}{c}\text { Mort } \\
\mathbf{( \% )}\end{array}$ & $\begin{array}{c}\text { MF } \\
\mathbf{( \% )}\end{array}$ & $\begin{array}{c}\text { Mort } \\
\mathbf{( \% )}\end{array}$ & $\begin{array}{c}\text { MF } \\
\mathbf{( \% )}\end{array}$ & $\begin{array}{c}\text { Mort } \\
\mathbf{( \% )}\end{array}$ & $\begin{array}{c}\text { MF } \\
\mathbf{( \% )}\end{array}$ & $\begin{array}{c}\text { Mort } \\
\mathbf{( \% )}\end{array}$ & $\begin{array}{c}\text { MF } \\
\mathbf{( \% )}\end{array}$ & $\begin{array}{c}\text { Mort } \\
\mathbf{( \% )}\end{array}$ \\
\hline Mongal & $7,5 \mathrm{a}$ & $20,32 \mathrm{ab}$ & $2,08 \mathrm{a}$ & $7,53 \mathrm{a}$ & $10,58 \mathrm{a}$ & $17,06 \mathrm{bc}$ & $11,71 \mathrm{a}$ & $5,39 \mathrm{a}$ & $10,11 \mathrm{a}$ & $2,8 \mathrm{a}$ \\
\hline Nadira & $4,82 \mathrm{a}$ & $8,35 \mathrm{~b}$ & $6,14 \mathrm{a}$ & $6,44 \mathrm{a}$ & $9,99 \mathrm{a}$ & $16,89 \mathrm{bc}$ & $17,54 \mathrm{a}$ & $2,49 \mathrm{a}$ & $10,38 \mathrm{~b}$ & $6,8 \mathrm{~b}$ \\
\hline Jaguar & $8,87 \mathrm{a}$ & $3,75 \mathrm{~b}$ & $3,12 \mathrm{a}$ & $5,39 \mathrm{a}$ & $10,54 \mathrm{a}$ & $12,00 \mathrm{c}$ & $12,03 \mathrm{a}$ & $7,73 \mathrm{a}$ & $13,92 \mathrm{~b}$ & $2,8 \mathrm{a}$ \\
\hline Thorgal & $6,2 \mathrm{a}$ & $32,12 \mathrm{a}$ & $0,00 \mathrm{a}$ & $4,35 \mathrm{a}$ & $5,21 \mathrm{a}$ & $28,90 \mathrm{abc}$ & $10,57 \mathrm{a}$ & $16,19 \mathrm{a}$ & $12,3 \mathrm{~b}$ & $5,9 \mathrm{a}$ \\
\hline Gempride & $6,82 \mathrm{a}$ & $4,52 \mathrm{~b}$ & $0,00 \mathrm{a}$ & $1,04 \mathrm{a}$ & $5,24 \mathrm{a}$ & $28,94 \mathrm{abc}$ & $14,59 \mathrm{a}$ & $16,23 \mathrm{a}$ & $14,97 \mathrm{~b}$ & $1,4 \mathrm{a}$ \\
\hline Rs & $9,19 \mathrm{a}$ & $4,43 \mathrm{~b}$ & $7,29 \mathrm{a}$ & $4,16 \mathrm{a}$ & $4,63 \mathrm{a}$ & $44,48 \mathrm{a}$ & $13,48 \mathrm{a}$ & $16,43 \mathrm{a}$ & $19,48 \mathrm{ab}$ & $2,0 \mathrm{a}$ \\
\hline FBT5 & $7,0 \mathrm{a}$ & $5,06 \mathrm{~b}$ & $5,00 \mathrm{a}$ & $5,16 \mathrm{a}$ & $5,67 \mathrm{a}$ & $29,87 \mathrm{abc}$ & $17,07 \mathrm{a}$ & $8,45 \mathrm{a}$ & $15,15 \mathrm{~b}$ & $7,2 \mathrm{~b}$ \\
\hline Lindo & $8,96 \mathrm{a}$ & $10,97 \mathrm{~b}$ & $3,08 \mathrm{a}$ & 0,00 & $5,11 \mathrm{a}$ & $35,94 \mathrm{ab}$ & $14,09 \mathrm{a}$ & $5,09 \mathrm{a}$ & $13,56 \mathrm{a}$ & $3,1 \mathrm{a}$ \\
\hline Moyenne & 7,19 & 11,05 & 3,47 & 4,14 & 7,17 & 26,40 & 15,83 & 9,02 & 14,16 & 3,91 \\
\hline Probabilité & 0,5890 & 0,0004 & 0,6788 & 0,0790 & 0,3766 & 0,0189 & 0,1282 & 0,3060 & 0,0010 & 0,0800 \\
\hline
\end{tabular}

MF = Maladie foliaire; Mort = Mortalité; Mon = Mongal; Thorg = Thorgal; Gemp = Gempride; Moyen = Moyenne; Prob $=$ Probabilité

\section{$5 \quad$ DISCUSSION}

5.1 Effet du site de la variété sur le nombre de plants récoltés: Les densités des plants issus de toutes les variétés ont été sensibles aux variations du site. En moyenne, le nombre de plants récoltés a été le plus important à Yako. Il a été suivi par celui de Salgo, ensuite, viennent les sites de Komgoussi et Loumbila qui ont occupé la troisième position. Le site de Kamboinsè a enregistré en moyenne un nombre de plants très faible comparativement aux autres sites. En fonction du cultivar, les densités de plants ont été très variables par site. Les variétés Thorgal, Gempride, Jaguard, Mongal et Nadira ont observé leur plus forte densité sur le site de Yako. Sur celui de Salgo, les variétés FBT5
Lindo et Rs01658654 ont enregistré leur meilleure densité. Globalement, sur le site de Kamboinsè les tomates Nadira, Jaguard et Mongal ont observé leurs plus faibles densités. Comparativement à ce dernier, cette variable a été légèrement meilleure sur le site de Loumbila pour les tomates Nadira, Jaguard, Gempride, Rs et Mongal, cependant, les valeurs obtenues ont été en-dessous de celles enregistrées à Kongoussi. Les différences dans les méthodes de travail et les conditions du milieu au cours de la période végétative ont influencé la survie des plants au cours de la période végétative et son peuplement à la récolte. A ce propos, d'autres études conduites par les auteurs Belaid (1996) et Buckman (1999) sur le blé ont établis 
une dépendance de la densité de la culture à la quantité de grains semés et au taux de survie des plantes. De même pour ces auteurs, les conditions climatiques avant et après semis, sont tous des facteurs qui influent le peuplement d'une culture. Les résultats ont confirmé qu'un bon peuplement résulte, en plus des autres facteurs de production, d'un bon comportement de la culture à la levée dans d'autres conditions agro-climatiques (Anonyme, 2008). Selon le type de croissance de la tomate, (déterminée, semi-déterminée et indéterminée), Naikal et al. (2005) recommandent respectivement des densités moyennes de 20000 plants/ha pour l'un et 27000 plants/ha pour les deux derniers types de croissance.

4.2 Effet du site et de la variété sur le nombre moyen du fruit par plant (Nbfrtpt): En générale faible par site de production, ce nombre moyen de fruits par plant a très peu varié par site. Cependant, les valeurs observées ont été en hausses et quasiment identiques sur les sites de Kongoussi et Lounbila, avec 7,40 et 7,16 fruits/plant respectivement. Les sites de Yako et salgo ont enregistré en moyenne des valeurs presque similaires et légèrement plus faibles respectives de 6,23 et 6,51 fruits/plant. Le site de Kamboinsé pour ce paramètre a observé 5,35 fruits/plant. S'agissant de la quantité de fruits récoltés par pied de tomate, les variétés testées n'ont pas été significativement différents. Cependant, pour certains cultivars ce paramètre a enregistré une amélioration: Nadira a été plus performant sur les sites de Salgo, Loumbila, Kamboinse et Yako avec 7,95; 7,92; 7,3 fruits et 6,3 fruits/plant respectivement; La variété Gempride de par ce paramètre a été meilleure sur les sites de Loumbila (12,9 fruits/plant) et Salogo (10,48 fruits/plant). Les cultivars suivants ont amélioré cette variable pour Jaguard à Kamboinse (6,2 fruits/plant) et Salogo (7,85 fruits/plant); Thorgal à Yako (6,35 fruits/plant) et à Salogo (6,11 fruits/plant), tandis que Lindo et Mongal ont été meilleures respectivement à Loumbila (7,87 fruits/plant) et à Salogo (6,63 fruits/plant). Indépendamment du site de production, il ressort de cette analyse générale que par pied de tomate, le nombre moyen de fruit a été plus élevé chez les cultivars Gempride (9,99 fruits) et Nadira (7,36 fruits), suivis des cultivars Jaguar (6,33 fruits), Lindo (6,66 fruits) et FBT5 (6,21 fruits). Les variétés Mongal et Thorgal ont enregistré respectivement 4,95 et 5,1 fruits/plant. Par rapport aux résultats de Kamara Muhuza (2016), qui a obtenu en moyenne pour la Mongal (8 fruits) et la Thorgal 4,58 fruits dans les conditions culture dans le sol enrichi de fumier de porc sous abri à Kisangani; il se dégage que les hybrides F1 Mongal et Thorgal présentent des valeurs numériques inferieures. Ces écarts peuvent s'expliquer par les génotypes et les conditions d'expérimentation. Selon Chaux et Foury (1994) le poids moyen et le nombre des fruits augmente lorsque les températures passent de 12 à $18^{\circ} \mathrm{C}$; ils diminuent au-delà. Cependant, le poids moyen de fruit est un composant important dans la production.

5.3 Effet du site et de la variété sur le poids moyen du fruit (PdMfrt): Le poids moyen du fruit a été meilleur à Kamboinsè, faible sur les sites de Lounbila et Komgoussi et très faible sur ceux de Salgo et Yako. Par contre, pour ce paramètre, les différents cultivars ont observé des différences hautement significatives. Pour Jaguard, cette variable a peu évoluée sur la majorité des sites testés, excepté Yako où à l'instar des cultivars Gempride et Nadira sa valeur a été très faible. Pour ce paramètre, les performances ont été fortes à Kongoussi pour la tomate Gempride et à Loumbila chez les cultivars Jaguard, Mongal, FBT5 et Thorgal. Les meilleurs chiffres ont été pour Gempride, Mongal, Rs01658654, Nadira et Jaguard à Salgo. La comparaison chez les hybrides de la moyenne de cette variable révèle pour les cultivars Mongal, Jaguard, FBT5, Rs01658654, Thorgal, Nadira, Gempride et Lindo des valeurs respectives de 55,99; 52,34; 46,$02 ; 45,4 ; 44,52 ; 43,22 ; 42,46$ et 41,88 g. En confrontant nos résultats avec ceux de Kamara Muhuza (2016), qui a trouvé des poids moyen pour les hybrides F1 Mongal (79,92 g) et F1 Thorgal $(82,53 \mathrm{~g})$ avec du fumier de porc et 
ceux de Tonganga (2016), qui a obtenu pour l'hybride F1Thorgal sciure de bois (92 g), nous constatons que les poids de fruits de l'hybride F1 Mongal (55,99 g) et F1 Thorgal (44,52 g) ont été inférieurs. De même l'hybride Thorgal (sciure de bois) a été supérieur à Thorgal (fumier de porc) par ce paramètre. Les résultats obtenus ont été en général faibles. Ces hybrides en temps normal enregistrent des poids moyen du fruit pour FBT5 (90-95 g), RS 01658654 (65 g), Thorgal (120 à $130 \mathrm{~g}$ ), Lindo, Mongal (100 à $120 \mathrm{~g}$ ), Nadira F (185 à $90 \mathrm{~g})$, Jaguar F (1100 à $110 \mathrm{~g}$ ) et pour Gempride de (80 à $100 \mathrm{~g})$. Ces variations observées pourraient être dues soit aux conditions du milieu, soit aux techniques culturales appliquées à la culture. Les périodes sèches et fraiches sont plus favorables à la production que les saisons pluvieuses et chaudes (Lannoy, 2001; Lokonga, 2015). Chaux et Foury (1994) confirment que le poids moyen et le nombre des fruits ainsi que la production précoce augmentent lorsque les températures passent de 12 à $18^{\circ} \mathrm{C}$; ils diminuent au-delà.

\subsection{Effet du site et de la variété sur le} rendement fruit (RdtFr): Les rendements obtenus n'ont pas été fondamentalement différents par cultivar de tomate. Par contre, ils ont été très variables d'un site à l'autre. Dans notre étude, les meilleurs rendements ont été enregistrés à Yako par les cultivars Rs01658654 (28,72 t/ha), Nadira (28,74 t/ha), Gempride (22,00 t/ha), Jaguard (18,6 t/ha), Thorgal (14,84 t/ha) et à Salgo par les variétés Gempride, Mongal, FBT5, Jaguard et Thorgal avec respectivement 21,$65 ; 20,3 ; 20,0 ; 17,46$ et 15,14 t/ha. Selon Messiaen et al. (2000), le rendement moyen de la tomate est d'environ $25 \mathrm{t} / \mathrm{ha}$ au niveau mondial. Au sud du Sahara ce rendement serait de 10 t/ha (Nono et al., 2001). Cependant, on a assisté à une baisse des rendements passés de 11,3 t/ha en 2010 à 9,7 t/ha en 2014 (FAOSTAT, 2016). Les meilleurs rendements ont varié entre 14,84 et 28,74 t/ ha, donc supérieurs aux valeurs obtenues au niveau sous régional et pour certains cultivars au niveau mondial. Ces résultats corroborent ceux des auteurs Soro et al. (2007) qui ont en Côte d'Ivoire ont obtenu des valeurs plus importantes (24 à 51 t/ha) en saison des pluies avec différentes variétés selon la séquence suivante: variétés d'Israël (T 3331 et T 3328) > variétés de Taiwan (CLN 2026 D4, CLN 2443 A, CLN 2443 B) > variété locale Petomech. En outre, le rendement d'un site à l'autre pour une même variété était très variable. Le rendement des variétés Gempride (21,65 t/ha), Mongal (20,3 t/ha), FBT5 (20,0 t/ha), Jaguard (17,46 $\mathrm{t} / \mathrm{ha})$ et Thorgal (15,14 t/ha) à Salgo ont été le triple de ceux obtenus à Loumbila et kongoussi et le quintuple des rendements observés à Kamboinsè. De même, sur d'autres sites, pour ces variétés les rendements ont évolué de faibles à très faibles. Par exemple, les rendements ont chuté pour Thorgal de 4,4 t/ha à (Loumbila et Yako) à 2,4 t/ha à Kamboinsè et pour Mongal de 6,77 t/ha à 1,6 t/ha. Les rendements des sites de Kongoussi, de Loumbila et plus encore de Kamboinsè ont été moins importants que ceux enregistrés sur les deux autres sites. Par ailleurs la mortalité des plants sur ces sites a été plus importante comparativement aux deux autres sites. Toutefois, seul 7,19\% des plantes à Kongoussi, $7,17 \%$ à Loumbila et 15,83\% à Kamboinsè ont été sensibles aux flétrissements contre 3,47\% de plants flétris à Yako et 14,16\% à Salgo. Les flétrissements des plants n'ont pas été les principales causes dans la mortalité des plantes de tomates sur l'ensemble des sites de productions. Toutefois, selon Déclert (1990), les faibles rendements de la saison sèche peuvent être attribués à la forte pression des maladies (TYLCV, et flétrissement bactérien) et des insectes sur la parcelle. Les conditions du milieu ainsi que les techniques culturales appliquées à la culture ont été capitales dans l'obtention des résultats. En effet, selon Chaux et Foury (1994), l'alimentation hydrique est un facteur important du rendement de la tomate. Aussi pour les auteurs Pervez et al. (2009), le déficit hydrique diminue le nombre de fruits par plant mais augmente la quantité de sucres chez les tomates. De même, pour Chaux et Foury (1994), les températures nocturnes élevées augmentent la précocité mais diminuent plutôt 
le rendement final, les fruits étant plus gros mais moins nombreux, tandis que les intensités lumineuses faibles et les températures élevées provoquent une réduction de la taille des fruits (Konnys, 2009). La croissance de la tomate est meilleure lorsque les maxima journaliers de température sont supérieurs à $10^{\circ} \mathrm{C}$ sans dépasser $30^{\circ} \mathrm{C}$, c'est ainsi que les rendements sont très satisfaisants en saisons sèche. Lorsque la température dépasse plus de $35^{\circ} \mathrm{C}$, la fructification est interrompue par défaut de fécondation (Kroll, 2001). La très faible implication des producteurs dans le suivi des tests sur certains sites lié au faible niveau d'instruction et de formation technique des producteurs peut aussi expliquer les rendements très faibles obtenus sur certains sites. Pour Ahouangninou et al. (2011), kanda et al. (2013), Wognin et al. (2013) et Naré et al. (2015), ces facteurs seraient un frein a une bonne utilisation des produits phytosanitaires par méconnaissance des bioagresseurs et du produit adéquat à utiliser en fonction de la cible contribuant à la réduire les rendements et la qualité de la production

\section{5 Effet du site et de la variété sur les} taux de maladies foliaires et de mortalité plants: Les proportions moyennes de plantes présentant des symptômes foliaires observées trois semaines après le repiquage ont été sensiblement identiques pour tous les cultivars sur les différents sites. Cependant, la variété Rs01658654 a enregistré des valeurs en légère hausse à Yako et Kongoussi respectives de 7,29 et $9,19 \%$. De même, les cultivars Mongal $(10,58 \%)$, Nadira $(17,54 \%)$ et FBT5 (15,83\%) ont été plus sensibles aux flétrissements à Loumbila, Kamboinsè et Salgo respectivement. La comparaison entre les sites montre que les périmètres de Salgo et Kamboinsè ont présenté les plus forts taux de maladies foliaires respectifs de 14,16 et $15,15 \%$. Plusieurs espèces de champignons dont notamment les espèces des genres Fusarium, Cladosporium, Colletotrichum, Curvuaria, Melanospora et Phoma présents sur presque tous les sites ont été impliquées dans le développement de ces infections. Des agents pathogènes bactériens causant la mortalité des plants ont également été rencontrés dans tous les sites. Ce son notamment les genres Ralstonia, Solanacearum, Erwinia et Carotovora. La différence non significative observée entre les variétés de tomate par rapport au flétrissement bactérien lors du test indique que la sensibilité à cette maladie n'a pas dépendu des variétés donc du matériel végétal. Ces résultats obtenus ne semblent pas corroborer les données de N'guessan et al. (2012) qui ont montré en Côte d'Ivoire différents niveaux de sensibilité au flétrissement bactérien chez la tomate allant des variétés hautement sensibles au plus résistantes. Par exemple, selon Van Der Vossen et al. (2004), la F1 Mongal est connue pour sa résistance au flétrissement bactérien et son adaptation au climat chaud et humide. Les pratiques culturales ont influencé dans notre étude la gestion du flétrissement bactérien. La jachère et la rotation adoptées sur les différents sites ont permis le maintien à un niveau acceptable de l'infection. Selon Fondio et al. (2010), la jachère ou la rotation culturale de la tomate avec d'autres cultures hormis la famille des Solanacées est un moyen de contrôle du flétrissement bactérien. Cependant, la présence des eaux stagnantes ont contribué à accroitre la sensibilité des cultivars Mongal (10,58\%), Nadira $(17,54 \%)$ et FBT5 $(15,83 \%)$ aux flétrissements à Loumbila, Kamboinsè et Salgo respectivement. Pour Poussier (2000), Van Elsas et al. (2001) et Cariglia (2007), l'excès d'eau ainsi que les eaux stagnantes constituent des sources de dissémination de la bactérie lorsque des racines affectées par la maladie se développent dans celles-ci. A cet effet, selon Naika et al. (2005), le drainage efficace des parcelles, en évitant la stagnation de l'eau est un moyen de gestion du flétrissement bactérien en culture de la tomate. Les températures audessus de $25^{\circ} \mathrm{C}$ favorisent la multiplication et la progression de la maladie (Cariglia, 2007). Toutefois, les flétrissements des plants ne semblent pas avoir une incidence majeure la culture d'autant plus qu'elles n'ont pas entrainé de défoliations importantes pouvant affecter significativement le développement des plantes du faite du niveau générale faible de l'infection 
des parcelles. Les taux de mortalité des plants des différentes variétés de tomate ont varié de 0 à $7,53 \%$ à Yako, 2,49 à 16,43\% à Kamboinsè, 3,75 à 20,32\% à Kongoussi, 1,4 à 6,8\% à Salogo et 12,0 à $44,48 \%$ à Loumbila. Parmi ces variétés testées, Thorgal a présenté des taux de mortalité élevés de 28,9 et 32,12\% respectivement à Loumbila et Kongoussi. A Loumbila, outre Thorgal, les cultivars Rs (44,48\%), Lindo

\section{CONCLUSION}

Les rendements par site ont évolué de 17,9 t/ ha (Nadira) - 21,65 t/ha (Gempride) à Salogo, 14,84 t/ha (Thorgal) - 28,72 (Rs01658654) à Yako, 4,4 t/ha (Thorgal) - 9,72 t/ha (Nadira) à kongoussi, 1,6 t/ha (Mongal) - 5,13 (Jaguard) à Kamboinse et à Loumbila de 4,4 t/ha (Thorgal) - 9,72 t/ha (Nadira). En moyenne, les sites de Salgo et Yako ont observé les plus forts rendements respectifs 17,44 et 19,04 t/ha. Sur les sites de Kongoussi, Loumbila et Kamboinsè les rendements ont été moins importants. Par ailleurs, sur ces derniers la mortalité des plants a été plus importante comparativement aux deux autres sites. Toutefois, seul 7,19\% des plantes à Kongoussi, $7,17 \%$ à Loumbila et $15,83 \%$ à Kamboinsè ont été sensibles aux flétrissements
$(35,94 \%) \quad$ Gempride $(28,94 \%)$ et FBT5 $(28,87 \%)$ ont également subi des pertes sensibles. La comparaison entre les différents sites a révélé que Loumbila (26,4\%) de taux moyen de mortalité des plantes, est le site le plus affecté par les flétrissements des plants. Les sites de Salogo (19,36\%) et Kongoussi $(11,05 \%)$ occupent la seconde et troisième place.

contre 3,47\% de plants flétris à Yako et 14,16\% à Salgo. Les flétrissements des plants n'ont pas été les principales causes dans la mortalité des plantes de tomates sur l'ensemble des sites de productions. Selon la moyenne de rendements, les meilleurs cultivars ont été par ordres décroissant Nadira, Rs01658654, Gempride, Jaguar, Thorgal, Mongal, FBT5 avec respectivement $13,87,10,79 ; 10,23 ; 9,66 ; 8,23$ et 7,08 t/ha. Les résultats obtenus sur les 5 sites ont montré une variabilité importante entre les sites. Ce qui est peut du à la maitrise des techniques de production qui n'ont pas été homogènes d'un site à un autre mais aussi aux conditions du milieu.

\section{REFERENCES BIBLIOGRAPHIQUES}

Anonyme: 2008. "Bilan des activités agrotechniques de l'Institut Techniques des Grandes Cultures", Algérie.

Belaid D: 1996. "Aspect de la céréaliculture algérienne", Ed- O.P.U, 217p.

Buckman WG: 1999. "Agriculture et fertilisation" Ed. Norsk hydro a.s., 258p.

Cariglia A: 2007. Lutte préventive contre le flétrissement bactérien en culture de la tomate hors-sol - Etat des connaissances et conseils. Pôle de protection des plantes, Réunion, StPierre. Chaux Cl. et Foury Cl: 1994 : Productions légumières. Tome III: légumineuses potagères, légumes fruits. Ed. Tec et Doc. Lavoisier. Paris. pp 145-231.

Déclert C: 1990. Manuel de phytopathologie maraîchère tropicale. In Cultures de Côte d'Ivoire. Paris, ORSTOM, 333 p.

FAOSTAT. 2016. Situation de la production de tomates au Burkina Faso. Disponible sur http://www.fao.org/faostat/fr/\#da ta/QC.

Fondio L, Djidji AH, N'gbesso MFDP. et Ochou OG: 2010. Evaluation des variétés de tomate et piment pour la tolérance au flétrissement bactérien, et multiplication des semences de piment. Rapport d'activités, Convention CNRA/AVRDC, CNRA, Bouaké, Côte d'Ivoire, 31p.

Houangninou C, Fayomi BE. et Martin T: 2011. Évaluation des risques sanitaires et environnementaux des pratiques phytosanitaires des producteurs 
maraîchers dans la commune rurale de Tori-Bossito (Sud-Bénin). Cabiers Agricultures $20 \quad$ (3): 216-222. DOI:10.1684/agr.2011.0485.

Kamara Muhuza M: 2016. Effet de fumier de porc sur le rendement de deux variétés hybrides F1 (Mongal et Thorgal) exotiques de tomate (solanum bcopersicum L.) cultives sous abri a Kisangani, Université De Kisangani, 39p.Thèse de Doctorat d'État ès Sciences Naturelles, Université de Ouagadougou, 290p.

Kanda M, Djaneye-Boundjou G, Wala K, Gnandi K, Batawila K. et Sanni A: 2013. Application des pesticides en agriculture maraîchère au Togo. VertigO - la revue électronique en sciences de l'environnement 13 (1): 1-17.

Konnys S: 2009.www.plantefrance.fr

Kroll R.: Les cultures maraîchères, Bruxelles, de Boek Université, 2001

Lannoy G: 2001. Cultures des légumes Légumes, in Raemaekers, R.H. éd. Agriculture en Afrique, DGCI, Bruxelles, pp 429-512.

Laumonnier R: 1979. Cultures légumières et maraîchères. Tome III. Ed. J. B. Baillière Paris. 274p.

Lokonga O: 2008. Caractérisation de la diversité génétique et fertilité pollinique in vitro des tomates (Lycopersicon esculentum Mill) de la région de Kisangani(R.D.Congo), DEA, inéd., Unikis 63p. MASA: 2013. Rapport final situation de référence filières agricoles, Ministère de l'Agriculture et de la Sécurité Alimentaire, Burkina Faso, 208p.

MAHRH : 2011. Rapport d'analyse du module maraîchage. Rapport d'étude phase 2 : RGA 2006- 2010, Ministère de l'Agriculture de l'Hydraulique et des Ressources.

MASA : 2013. Rapport final situation de référence filières agricoles, Ministère de l'Agriculture et de la Sécurité Alimentaire, Burkina Faso, 208p.
Messiaen CM, Migliori A. et Maison P: 2000. Effet de la Mosaïque du tabac (TMV) sur la croissance et la fructification des cultures de tomate de plein champ dans le Sud-est de la France. Etude de Virologie. Ann. Epibyt., 19(4): 93-102

Naika S, Lidt de Jeude VJ, Goffau De M, Hilmi M. et Van Dam B: 2005. La culture de la tomate: production, transformation et commercialisation, Fondation Agromisa et CTA, Wageningen, Agrodok 17, 105p.

Naika S, Van Dam B. \& Florijn A: 2005. La Culture de la Tomate, Production, Transformation et Commercialisation (5é édn révisée). Agromisa Foundation, coll. Agrodok: Wageningen, 17p.

Naré RWA, Savadogo PW, Gnankambary Z, Nacro HB. et Sedogo MP: 2015. Analyzing risks related to the use of pesticides in vegetable gardens in Burkina Faso. Agriculture, Forestry and Fisheries 4(4):

165-172.

DOI:10.11648/j.aff.20150404.13.

Nono WR, Swai IS. and Chadha ML: 2001. Management of vegetable diseases in Eastern and Southern Africa: case study of tomato, In Anonym, Proceedings of the workshop on vegetable research and development in West Africa. Eds. AVRDC Africa Regional Program, Arusha, Tanzania, pp. 19-31.

Poussier S: 2000. Exploration de la diversité génétique de Ralstonia solanacearum, agent du flétrissement bactérien. Détection et dynamique dans les réservoirs d'inoculum. Ph.D thesis, Rennes I, Rennes, France, 149p.

Soro S, Doumbia M, Dao D, Tschannen A. et Girardin O: 2007. Performance de six cultivars de tomates Lycopersicon esculentum Mills. contre la jaunisse en cuillère des feuilles, le flétrissement bactérien et les nématodes à galles. Sciences \& Nature, 4(2): 123-130.

Tonganga K : 2016 : Influence de sciures des bois décomposées sur la croissance et le rendement des variétés hybride F1 étrangères (Thorgal et Mongal) de 
tomate (solanum lycopersicum L.) cultivée sous abri à Kisangani, mémoire inédit. F.S., UNIKIS, 38P

Uyikuru PI: 2010. Etude d'hybridation des quelques variétés des tomates (Solanum lycopersicum L) locales et étrangère ROMA cultivées à Kisangani et analyse génétique des hybrides F1, TFC inédit., Fac Agro., UNIKIS, 39p.

Van Elsas JD, Kastelein P, De Vries PM. and Van Overbeek LS: 2001. Effects of ecological factors on the survival of Rasltonia solanacearum bv.2 in irrigation water. Revue Canadienne de Microbiologie, 47(9): 842-854. 